\title{
Utilisation of CF/Sawdust Reinforced Epoxy Hybrid Composites on Mechanical Properties
}

\author{
M. Ashok Kumar*, T. Maruthi Chowdary, K. Chandra Sekhar Balaji, \\ E. Dhanunjaya Goud, S. Nagaraju, K. Shaik Ahmmed, B. Raja Sekhar \\ Department of Mechanical Engineering, Dr. KV Subba Reddy \\ Inst of Technology-Dupadu, Kurnool-518218(AP) \\ *E-mail address: ashokkumarmala7@gmail.com
}

\begin{abstract}
Keywords: hybrid fibres; sawdust; carbon fibre; mechanical properties
\end{abstract}
\begin{abstract}
This paper presents the performance of short carbon fibre (CF) reinforced and filled with sawdust (SD) hybrid epoxy composites were evaluated. The results showed that hybridisation of carbon fibre and sawdust was in similarity to $\mathrm{EP} / \mathrm{CF}$ hybrid composites. Effect of fibre orientation in matrix and the analysis and fracture surface was undertaken. The mechanical properties of injection moulded, chopped carbon fibre/sawdust/epoxy hybrid composites were investigated by considering the effect of hybridisation by these two fillers. It was observed that the tensile, flexural, and impact properties of the filled epoxy were higher than those of unfilled epoxy. The effect of filler on epoxy matrix subjected to the tensile strength and modulus was studied and compared with the rule of hybrid mixtures. The effect of filler on epoxy matrix subjected to the tensile strength and modulus was studied and compared with the rule of mixture. The actual results are marginally low as compared with the values obtained by the rule of hybrid mixtures (RoHM).
\end{abstract}

\section{INTRODUCTION}

In every automobile manufacturing industry, the natural fibres are used because of their adaptability to suit different situations and the relative ease of combinations with other materials to serve specific purpose and exhibit desired properties. Ubiquitous plastics usages are inevitable in these days as it is versatile material that lends itself to many uses. The turnaround in favor plastic happened not just because of color and durability for household products, and also plastics is an accessory became fashionable and trend setters. As a matter of fact, aircrafts and cars are made of composites to lighten their weight. Fiber reinforced rubber composites are of tremendous importance both in end-use applications and the area of research and development. These composites exhibit the combined behaviour of the soft, elastic rubber matrix and the stiff, strong fibrous reinforcement. The development of fiber reinforced rubber composites has made available polymers that are harder than aluminium and stiffer than steel. Generally short fiber reinforced rubber composites has become popular in industrial fields because of the processing advantages and increase in strength, stiffness, modulus and damping. The design of a short fiber reinforced rubber composite depends on several factors such as the aspect ratio of the fiber, control of fiber orientation and dispersion and existence of a strong interface between fiber and rubber. Cellulosic fibers are derived from many renewable resources and have many desirable properties for reinforcement of thermoplastics such as low density, high stiffness and low cost. The use of waste silk fiber and jute fiber in natural rubber has also been studied. Recent studies exhumed the incorporation of bamboo fiber in natural rubber would significantly improves performance has been investigated. Sisal fiber is one of the strongest fibres, which can be used for several applications. Oil palm fibers are hard and tough and have found to be a potential reinforcement in phenolformaldehyde resin. Among the different natural fibres sisal and oil palm fibres appear to be promising materials because of the high tensile strength of sisal fiber and toughness of oil palm fiber. Therefore any composite comprising of these two fibres will exhibit the above desirable properties of the individual constituents [1-22]. The present study deals with the optimization of sisal and oil palm fiber lengths in natural rubber composites. Thermoplastics occupy only a small 
percentage of the advanced composite market, while thermoset (i.e. Epoxy) materials contribute to more than 70 per cent. Due to their inbuilt entanglement structure, these resins are the most important polymers when it comes to high performance. Epoxy is a versatile and widely accepted matrix material for fabrication of advanced composites, hardware components, electrical circuit board materials and missile equipment, because of its excellent bonding, thermal, mechanical, dielectric and aging characteristics. Epoxy resins are widely used as coatings, adhesives, moulding compounds, and polymer composites because of their superior thermomechanical properties and excellent processability. However, the use of thermoset materials is often limited because of low toughness property. Many authors were touch upon EP/GF combination composites. However, $\mathrm{EP} / \mathrm{CF} / \mathrm{SD}$ combination expected to impart significant results. Therefore, authors zero in on $\mathrm{EP} / \mathrm{SD} / \mathrm{CF}$ hybrid composites. This paper attributes breakthroughs in short EP/CF/SD hybrid composites. The composites were pre-pared by extrusion compounding and using injection moulding techniques. In the present research, the effects of hybridisation by chopped CF and SD on the tensile and flexural properties of the hybrid EP/CF/SD composite were made. Since the mechanical properties of CF and SD differ greatly, the hybrid effect would likely to exist for their hybrid reinforced composites. The hybrid effects have been calculated using the rule of hybrid mixtures for the tensile strength, modulus, flexural strength and modulus.

\section{MATERIALS AND METHODS}

Carbon fibres, type T700S $^{\circledR}$ was obtained from Toray Industries, Inc., Tokyo, Japan. The epoxy (Araldite-LY 556 and Amine Hardener- HY 951) employed in this study was Ciba-Geigy of India Limited. In addition, the glass fibre (density: $350 \mathrm{~g} / \mathrm{m}^{2}$ ) was supplied by Saint Gobain Industries Ltd., Bangalore, India with an aspect ratio 250. The particulate type of sawdust used for this research was supplied by Sree composites, Hyderabad. The compositions of prepared specimens are given in Table 1. The extruder used was a twin screw extruder (JSW, Japan TEX$30 \mathrm{~A}$ ) with a diameter of $25 \mathrm{~mm}$ and machine capacity of $20 \mathrm{~kg} / \mathrm{h}$ having single feeding point. The composite was prepared by feeding the CF and SD in the polymer melt. The compounded extrudates were immediately quenched into water and cooled in air to ambient temperature. Then the extrudates strands were chopped into granules with the help of cutter and dried. All the specimens were then injection moulded using L\&T injection moulding machine with the parameters listed. Test specimens for the evaluation of mechanical properties were prepared. The tensile and flexural properties were determined using 5 samples of each composition

\section{SPECIMEN PREPARATION}

The composite was prepared by hand layup technique by rule of hybrid mixtures. Firstly, glass moulds were prepared based on ASTM standards with $15 \times 15 \times 3 \mathrm{~cm}^{3}$. Then filler was kept in the oven for half an hour to remove moisture. Then mould surfaces were sprayed with polyvinylalcohol in order to retain the shape of the casting after it is being cured while it is being taken out from the oven. A layer of modified epoxy was poured into the mould upon which CF was stacked randomly by parts[20]. Then the SD was mixed well with epoxy using mechanical stirrer until it mixture for no air bubbles. Care was taken to keep the mould flat using spirit level while mixture is being poured. Once the mixture poured completely in to the mould then thin OHP sheet was rolled over gently to keep the mould under subjected compression. Then the mould kept aside for 24hours curing, then it is taken into the oven to make sure to melt the mould releasing agent ought to be melt properly. Then the casting should be taken out from the mould using spatulas and knifes. Then the composites were cut in to ASTM sizes for testing. Tensile strength, flexural (bending) tests were carried out on par with ASTM D 53455. Tensile and flexural tests were performed on Instron universal testing machine (3369). The cross head speed was maintained 50 $\mathrm{mm} / \mathrm{min}$. All the tests were accomplished at a room temperature of $23^{\circ} \mathrm{C}$. At least, 5 samples were tested for each composition and results were averaged. Scanning electron microscopy (SEM) studies of the fractured surface of the tensile specimen were carried out on a Joel (6380LA, Japan). 
The specimen was sputter-coated with gold to increase surface conductivity. The thermal characteristics TGA, DSC measured on polymer composites using SDT Q600 TGA/DSC (TA Instruments) at a rate of $10^{\circ} \mathrm{C} / \mathrm{min}$ under nitrogen flow measurements were carried out at $20^{\circ} \mathrm{C}$ temperature, $40 \%$ relative humidity.

\section{RESULTS AND DISCUSSION}

Table 1. Different composition of samples with varying proportions of matrix, fiber and filler contents.

\begin{tabular}{llll}
\hline Sample & $\begin{array}{l}\text { Tensile strength } \\
(\mathrm{MPa})\end{array}$ & $\begin{array}{l}\text { Tensile } \\
\text { modulus } \\
(\mathrm{MPa})\end{array}$ & $\begin{array}{l}\text { Elongation at } \\
\text { Max. Force }(\%)\end{array}$ \\
\hline S1 & 25.90 & 460.11 & 11.2 \\
S2 & 35.26 & 781.69 & 8.5 \\
S3 & 49.23 & 854.02 & 10.2 \\
S4 & 40.14 & 624.07 & 9.2 \\
S5 & 41.52 & 635.00 & 8.7 \\
S6 & 32.58 & 456.75 & 8.1 \\
\hline
\end{tabular}

The results obtained from mechanical tests are shown in Table 2. The results are also obtained graphically in Fig. 1. From the above table it has been observed that, $\mathrm{S}_{1}, \mathrm{~S}_{2}$ and $\mathrm{S}_{6}$ samples tensile strength was 25.90, 35.26, 32.58MPa respectively, and these have deprived of SD particulates, thus there are remote chance of good strengths.

Table 2. Mechanical properties of EP/CF/SD hybrid composites.

\begin{tabular}{llll}
\hline Sample & EP $(\mathrm{wt} \%)$ & $\mathrm{CF}(\mathrm{wt} \%)$ & $\mathrm{SD}(\mathrm{wt} \%)$ \\
S1 & 100 & 0 & 0 \\
S2 & 60 & 40 & 0 \\
S3 & 60 & 30 & 10 \\
S4 & 60 & 20 & 20 \\
S5 & 60 & 10 & 30 \\
S6 & 60 & 0 & 40 \\
\hline
\end{tabular}

On other hand for $\mathrm{S}_{3}, \mathrm{~S}_{4}, \mathrm{~S}_{5}$ samples are filled with SD particles, and so is tensile strength were significantly improved 49.23, 40.14, 41.54 MPa respectively. Reasons attributes for improved performance was due to the increased surface aspect ratio by the CF and SD might be high when compared with composites with no SD particles. Moreover, another reason was bonding and interface between the filler/fiber with matrix was good. Addition of filler makes stiffening effect of the composite and the similar observations were noticed in old literatures. Tensile modulus, $\mathrm{S}_{3}$ 
modulus was good when compared to other samples, and the reason was more SD particle was conceded in that sample consequently. The attributed reasons are, when inclusion of filler in the matrix leads to significant increase in tensile modulus. The addition of rigid layers increases the stiffness in the matrix. This development is well explained by the percolation theory. According to this theory there is a matrix zone around each filament affected by stress concentration. If the distances between filaments are small enough, the zones join together and form a percolation network, which increase the tensile modulus [11, 13, 19, 24, 26].

Moreover, the elongation at break $(\varepsilon)$ of the composite was not affected significantly by increasing the fiber length shows in Table 2. The percentage elongation at break of the composites is lower than that of the matrix. This could be affected of low fracture strain and the poor adhesion between the matrix and the fibers [7]. Fig. 2 shows the effect of glass transition temperature as a function of temperature for the $S_{3}, S_{4}, S_{5}$ specimens. In fact for $S_{5}$ sample was having good peak than the $S_{4}$ and $\mathrm{S}_{3}$ samples.

The SEM micrograph of the failure surfaces was used for direct observation of composite structure, and particularly to examine the resin fiber interface. The net result of SEM is that the nature of the differing interactions such as the physical mixing of matrix and sizing resins and the nature of chemical absorptions at the fiber surface give rise to an interphase region as opposed to a distinct the matrix in the fiber-reinforced composite is to transfer the load to the stiff fiber through shear stress at the interface. This process requires a good bond between the polymeric matrix and fiber [9]. Fig. 3(a) shows the brittle nature of the neat epoxy, this may be reason for improved performance and also there were no voids were identified. The interface between fiber and matrix is shown in Fig. 3(b) for sample $\mathrm{S}_{3}$.It is showed that $30 \mathrm{~mm}$ fibers length of composite have a good adhesion between matrix and fiber. The load acting on the matrix has to be transferred to the reinforcement via the interface [10]. Thus, reinforcement must be strongly bonded to the matrix if their high strength and stiffness are to be imparted to the composite. It is also noticed that the fiber failed by tearing but no interfacial failure is observed. There are traces of matrix is still adhered to the fiber. This in an indication that the adhesion between fiber and matrix was not lost and the failure process was dominated by the matrix material properties [11]. Figure 3(c), it is shown that there was a small gap between fiber and matrix which means a poor adhesion or interfacial bonding for $2 \mathrm{~mm}$ in length for the sample $\mathrm{S}_{5}$. The void and small gap formed was probably caused by incomplete wettability or bonding between matrix resin and fiber during the fabrication of composites [12-13]. 


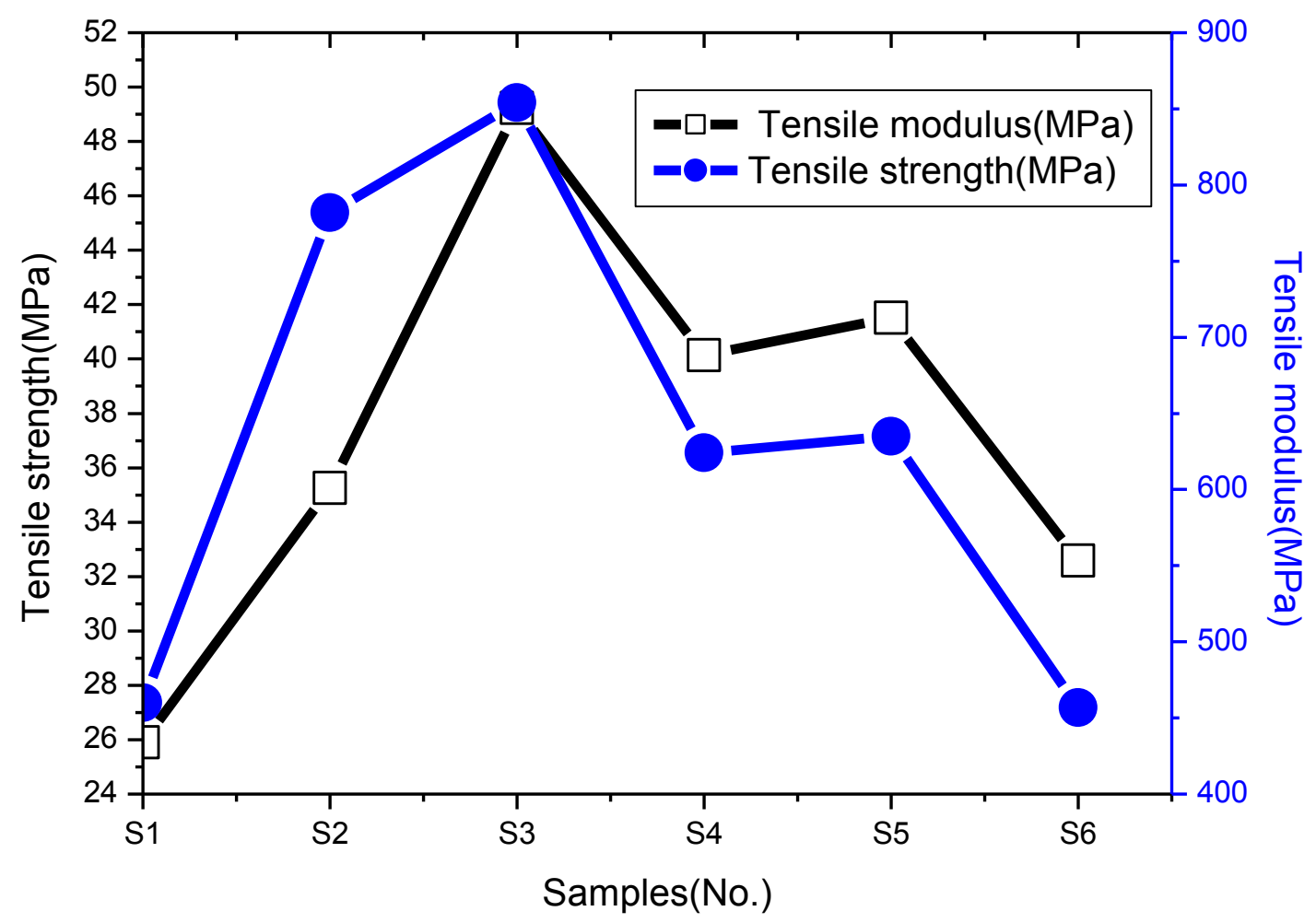

Fig.1 Tensile strength and modulus properties of SD/CF/EP hybrid composites as a function of SD \& CF.

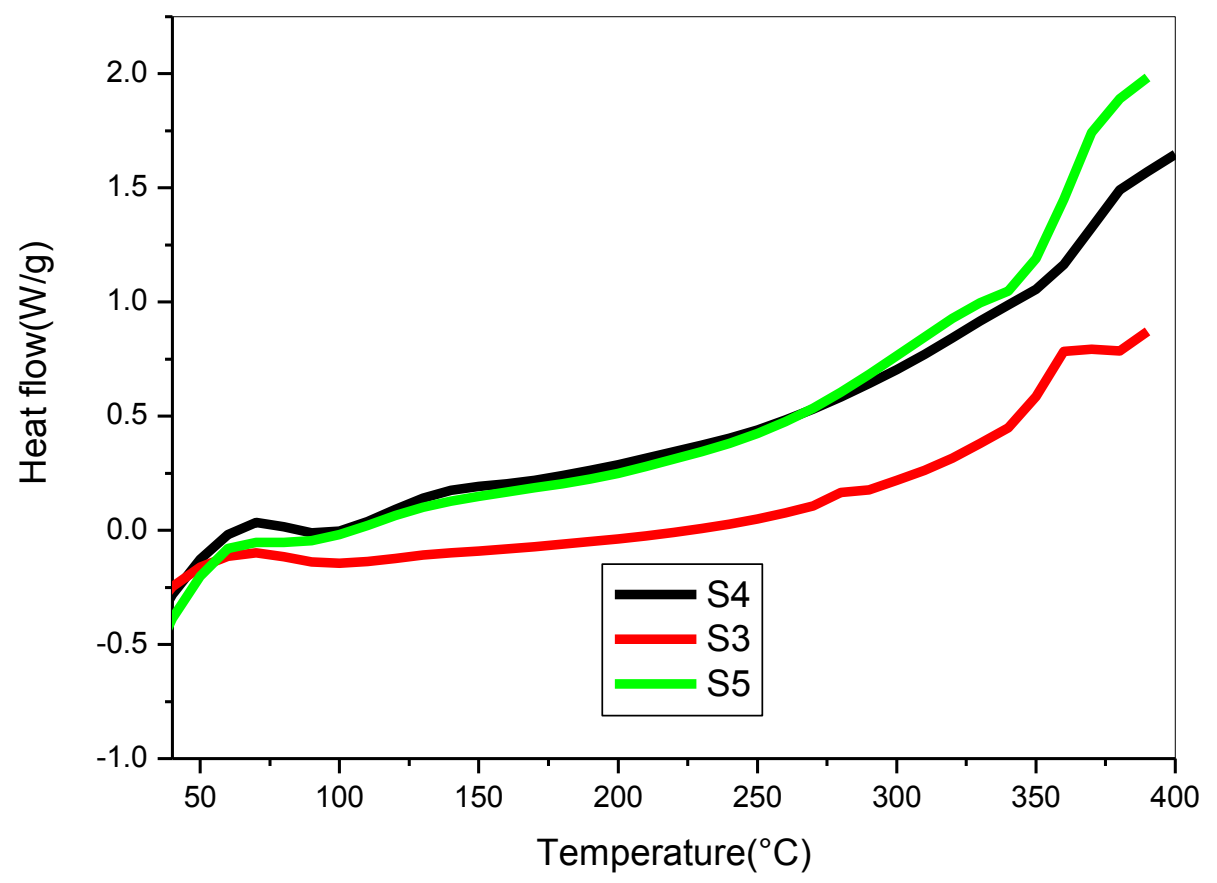

Fig.2 Differential Scanning calorometry properties of SD/CF/EP hybrid composites as a function of $\mathrm{SD} \& \mathrm{CF}$. 


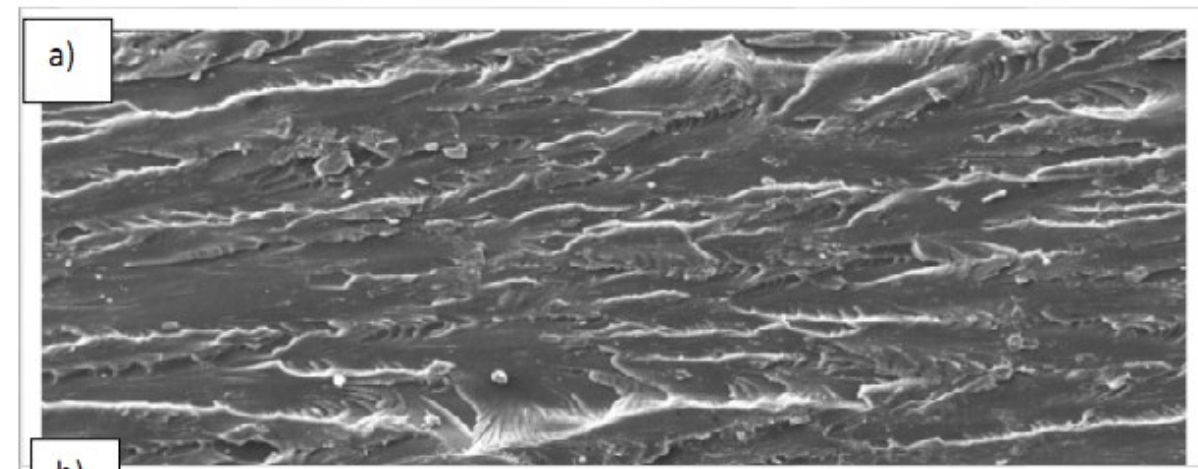

b)

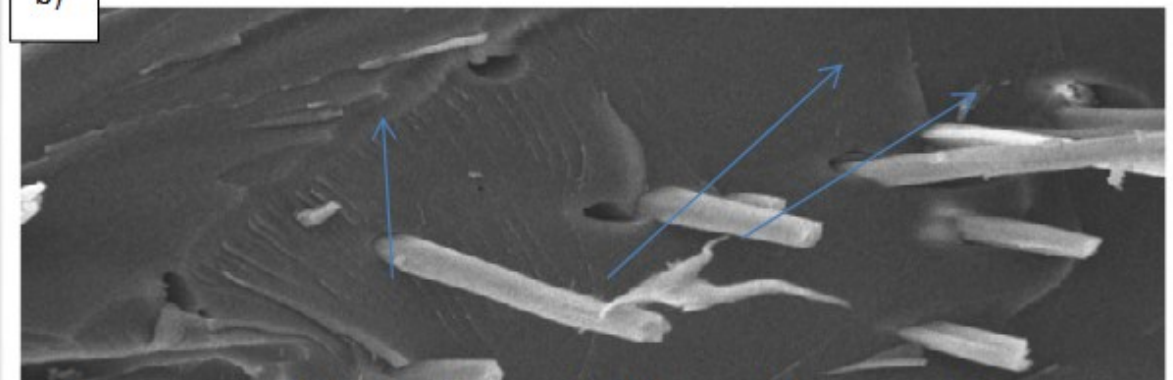

Improved interface at fibers the matrix
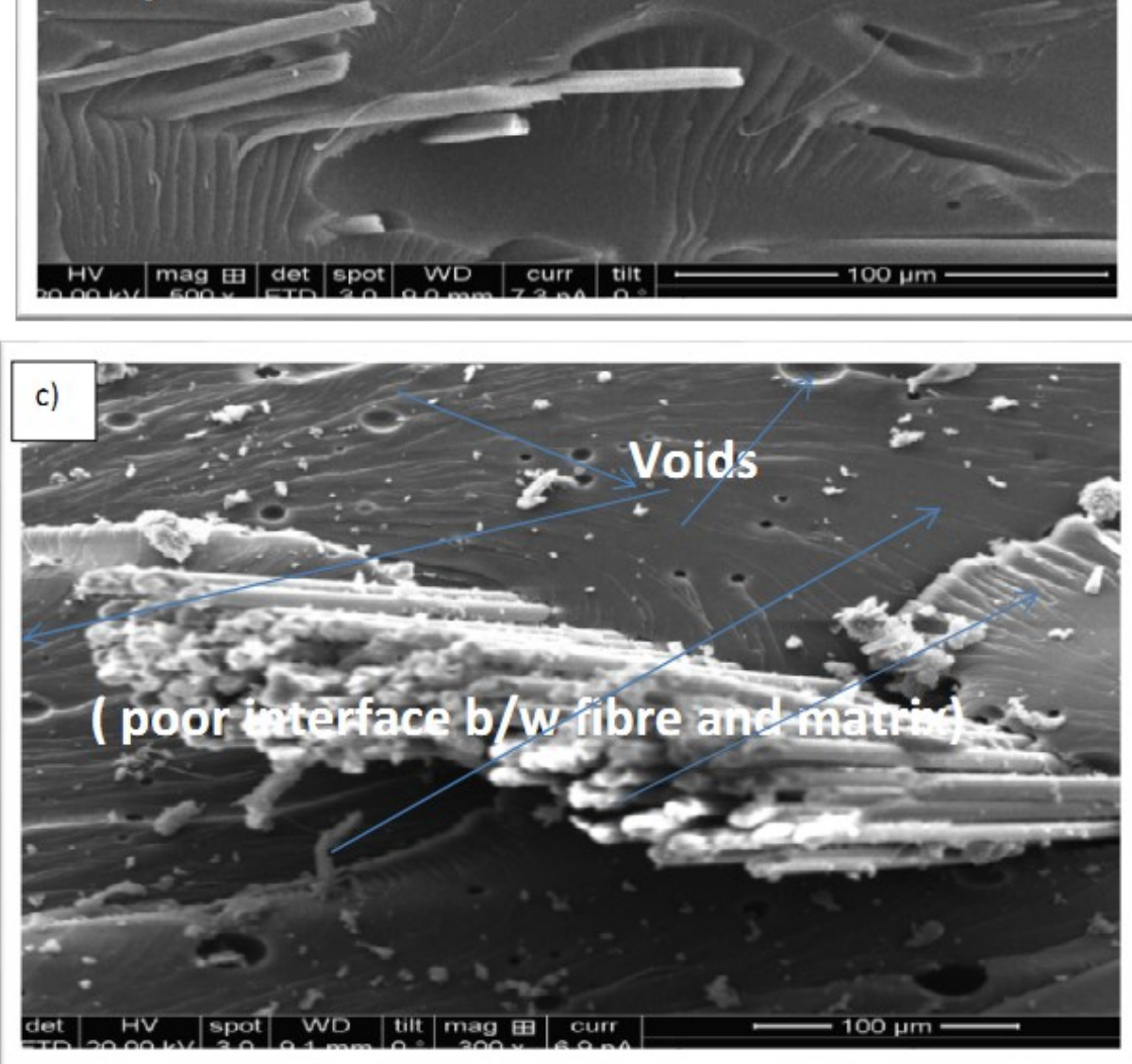

Fig.3: SEM analysis of sample (a) S1; (b) S3 and (s6) of SD/CF/EP hybrid composites.

\section{CONCLUSIONS}

In the present research epoxy filled with sawdust and carbon fiber hybrid composites were synthesised and evaluated. Tensile strength and modulus were significantly improved for the for the $\mathrm{S}_{3}$ sample. The reasons were attribute that, the improved surface area through the SD and CF played vital role in performance improvement. 


\section{Acknowledgements}

Authors would like to thank the Department of Mechanical Engineering, G.Pulla Reddy Engineering College, Kurnool, Department of Material Science and metallurgy, IISc Bangalore, and Department of Polymer Science and Technology for providing the characterization in time in spite of their busy schedules.

\section{References}

[1]Räsänen V, Penttala V. The $\mathrm{pH}$ measurement of concrete and smoothing mortar using a concrete powder suspension. Cem Concr Res 2004; 34(5):813-820.

[2]Edwards KL. An overview of the technology of fiber-reinforced plastics for design purposes. Mater Des 1998;19(1-2):1-10.

[3]Bahadur S, Zheng Y. Mechanical and tribological behaviour of polyester reinforced with short glass fibers. Wear 1990;137(2):251-66.

[4]Pihtili H, Tosun N. Effect of load and speed on the wear behaviour of woven glass fabrics and aramid fibre-reinforced composites. Wear 2002;252:979-84.

[5]Pihtili H, Tosun N. Investigation of the wear behaviour of a glassfibre- reinforced composite and polyester resin. Compos Sci Technol 2002;62:367-70.

[6]Bhawani ST, Michael JF. Tribological behaviour of unidirectional graphite-epoxy and carbonPEEK composite. J Wear 1993(162- 164):385-96.

[7]Myshkin NK, Petrokovets MI, Kovalv AV. Tribology of polymers: friction, wear, and masstransfer. J Tribol Int 2005;38:910-21.

[8]Sampathkumaran P Kishore, Seetharamu S, Murali A, Kumar RK. J Reinforce Plast Compos 1999; 18(1):55-62.

[9]Sampathkumaran P Kishore, Seetharamu S, Vynatheya S, Murali A, Kumar RK. SEM observations of the effects of velocity and load on the sliding wear characteristics of glass fabric-epoxy composites with different fillers. Wear 2000; 237:20-7.

[10] Collyer AA. Rubber toughened engineering materials. London: Chapman and Hall; 1994.

[11] El-Tayep NS, Gadelrap RM. Friction and wear properties of E-glass fiber reinforced epoxy composites under different sliding contact conditions. Wear 1996;192:112-7.

[12] Chand N, Naik A, Neogi S. Three-body abrasive wear of short glass fibre polyester composite. Wear 2000; 242:38-46.

[13] Rochdi EH, Bigaud D, Ferrier E, Hamelin P. Ultimate behaviour of CFRP strengthened RC flat slabs under a centrally applied load. Compos Struct 2006; 72(1):69-78.

[14] Colomb F, Tobbi H, Ferrier E, Hamelin P. Seismic retrofit of reinforced concrete short columns by CFRP materials. Compos Struct 2008; 82(4):475-487.

[15] Porter ML., Mehus J, Young K, Barnes B, O’Neil EF. Aging degradation of fibre composite reinforcement for concrete structures. In: Advanced comp mats in bridges and structures, 2nd int conference, Canada; 1997. p. 641-648.

[16] Abanilla MA, Li Y, Karbhari M. Durability characterization of wet lay-up graphite/epoxy composites used in external strengthening. Compos Part B: Eng 2006;37(2-3):200-12.

[17] Won JP, Park CG. Effect of environmental exposure on the mechanical and bonding properties of hybrid FRP reinforcing bars for concrete structures. J Compos Mater 2006;40(12):1063-76. 
[18] Hammami A, Al-Ghuiliani N. Durability and environmental degradation of glass-vinylester composites. Polym Compos 2004;25(6):609-616.

[19] Rahman AH, Kingsley C, Richard J, Crimi J. Experimental investigation of the mechanism of deterioration of FRP reinforcement for concrete. In: Proc 2nd intl conf on fibre comp in infrastructure ICC'98, Tuscan, vol. 2; 1998. p. 501-511.

[20] Chen Y, Davalos JF, Ray I, Kim HY. Accelerated aging tests for evaluations of durability performance of FRP reinforcing bars for concrete structures. Compos Struct 2007;78(1):101-11.

[21] Hamelin., Réparation et renforcement des structures en béton au moyen des matériaux composites. Document scientifique et technique, Association Française de Genie Civil (AFGC), Décembre; 2003.

[22] Gillham JK. The TBA torsion pendulum: a technique for characterizing the cure and properties of thermosetting systems. Polym Int 1997;44(3):262-276.

[23] Marouani S, CurtiL L, Hamelin P. Composites realized by hand lay-up process in a civil engineering environment: initial properties and durability. Mater Struct 2008;41(5):831-851. 